Check for updates

Cite this: RSC Adv., 2019, 9, 7767

\title{
Grape pomace as a biosorbent for fluoride removal from groundwater $\dagger$
}

\author{
Yangzhong Zhang ${ }^{a}$ and Kai Huang (D) *ab
}

This study presents a new type of biomass material for defluoridation from water; the material was prepared by loading tetravalent zirconium ions onto grape pomace produced from grape juicing and wine factories. Experiments showed that the optimum $\mathrm{pH}$ of defluoridation is around 3.0, and the fluorine removal efficiency could reach $96.13 \%$ for one-time contact. In batchwise adsorption tests, it was very interesting to find that even at $\mathrm{pH}$ values near 10, at which traditional adsorbents usually do not function for defluoridation, the removal efficiency of fluoride was still more than $90 \%$ for the $\mathrm{Zr}(\mathrm{IV})$-loaded grape pomace (Zr(IV)-GP) biosorbent; proton release from Zr(IV)-GP was confirmed to cause an automatic decrease of the $\mathrm{pH}$, which can save additional acid consumption in the case of one-time use and render the defluoridation more convenient and efficient. The maximum adsorption capacity of Zr(IV)-GP was $7.54 \mathrm{mg} \mathrm{g}^{-1}$; as a comparison, the maximum adsorption capacities of zirconium-loaded strongly acidic ion exchange resin D001 and zirconium-loaded weakly acidic ion exchange resin D113 were evaluated to be $4.85 \mathrm{mg} \mathrm{g}^{-1}$ and $1.14 \mathrm{mg} \mathrm{g}^{-1}$, respectively. The effects of coexisting anions, such as $\mathrm{Cl}^{-}, \mathrm{NO}^{3-}$, $\mathrm{SO}_{4}{ }^{2-}, \mathrm{CO}_{3}{ }^{2-}$ and $\mathrm{HPO}_{4}{ }^{2-}$, on the fluorine removal efficiency were also examined; it was found that $\mathrm{CO}_{3}{ }^{2-}$ and $\mathrm{HPO}_{4}{ }^{2-}$ anions had drastically adverse effects on defluoridation, while $\mathrm{Cl}^{-}, \mathrm{NO}^{3-}$, and $\mathrm{SO}_{4}{ }^{2-}$ appeared not to interfere. Real groundwater containing $1.8 \mathrm{mg} \mathrm{L}^{-1}$ fluoride sampled from Guanzhuang Village in Haixing County of Hebei Province was used for defluoridation through a continuous column adsorption process; it was found that pre-adjusting the groundwater $\mathrm{pH}$ affected the purification efficiency drastically, i.e., the time of the breakthrough point for the inlet groundwater $\mathrm{pH}$ at 3.0 was about 8 times longer than that at the original $\mathrm{pH}$ of 8.18. In addition, the $\mathrm{Zr}(\mathrm{IV})$ - GP adsorbent retained good adsorption capacity even after 3 cycles of adsorption-desorption-adsorption operations, indicating that the synthesized zirconium-loaded grape pomace is a very promising new fluorineremoving material for groundwater purification.

Received 6th January 2019

Accepted 22nd February 2019

DOI: $10.1039 / c 9 r a 00109 c$

rsc.li/rsc-advances the world are drinking groundwater with a fluoride concentration of more than $1.5 \mathrm{mg} \mathrm{L}^{-1}$; the most serious situation is in India. According to open reports, more than 66 million people in India suffer from fluorosis, including 4 million children under the age of $14 .^{7-9}$ Therefore, solving the problem of fluorine pollution in drinking water has become one of the main tasks of researchers worldwide.

There are many techniques for removing fluoride from water, such as electrodialysis, ${ }^{10,11}$ ion exchange, ${ }^{12,13}$ nanofiltration, ${ }^{\mathbf{1 4 - 1 6}}$ reverse osmosis, ${ }^{17}$ precipitation, ${ }^{18}$ and adsorption. ${ }^{19-22}$ Electrodialysis, ion exchange, nanofiltration and reverse osmosis are all efficient methods for defluoridation; however, they are complicated, costly, and impractical for some less developed and developing countries. The precipitation method usually uses a calcium salt to convert fluoride in water into a calcium fluoride precipitate for removal. This is a simple and low-cost fluorine removal method; however, it is only useful for water containing high concentrations of fluorine. In water with low concentrations of fluorine, it is difficult to decrease the fluoride in water to below $1.5 \mathrm{mg} \mathrm{\textrm {L } ^ { - 1 }}$ by this method. In
${ }^{a}$ School of Metallurgical and Ecological Engineering, University of Science and Technology Beijing, Xueyuan Rd 30, Haidian District, 100083, Beijing, China. E-mail: khuang@metall.ustb.edu.cn; Tel: +86-13552537538

${ }^{b}$ Beijing Key Lab of Green Recycling and Extraction of Rare and Precious Metals, University of Science and Technology Beijing, Xueyuan Rd 30, Haidian District, 100083, Beijing, China

$\dagger$ Electronic supplementary information (ESI) available. See DOI: 10.1039/c9ra00109c 
contrast, adsorption for fluorine removal is being extensively studied by many researchers because of its low cost, simple operation, and abundant raw material sources. ${ }^{23-26}$ In recent years, various adsorbents have been reported for the removal of fluoride in water, such as activated carbon, ${ }^{27,28}$ activated alumina, ${ }^{29-31}$ bone charcoal, ${ }^{32-34}$ ion exchangers loaded with high-valent metals, ${ }^{35,36}$ and biosorbents loaded with rare earth elements. ${ }^{37}$ However, these adsorbents may have low selectivity and experience interference from other anions in water, resulting in poor adsorption efficiency. For example, defluoridation using activated aluminum requires frequent elution due to its very small adsorption capacity for fluoride in practical cases; it also inevitably produces soluble aluminum ions in the water, which have been recognized as harmful to human health. Therefore, it is quite necessary to develop new cost-effective adsorbents for defluoridation of drinking water.

In this study, a novel fluorine-removing material was designed in which zirconium ions are loaded onto discarded grape pomace, which is abundantly produced in grape juicing and wine factories. Zirconium is a typical rare metal that mostly exists in the tetravalent state in aqueous solutions and has a strong tendency to hydrolyze in water to form hydrate species such as $\mathrm{ZrO}^{2+}-(\mathrm{OH})_{n}$; due to these properties, it is usually used as the basic functional component for anion exchange. Preliminary experiments showed that the Zr-loaded grape pomace gel had high efficiency and good selectivity for defluoridation. The development of this adsorbent material may provide a valuable reuse for grape waste. In order to compare the effects of the matrix materials on the defluoridation efficiency, a strongly acidic ion exchange resin, D001, with $-\mathrm{SO}_{3} \mathrm{H}$ functional groups (abbreviated as $\mathrm{Zr}$ (IV)-D001 hereafter) and a weakly acidic ion exchange resin, D113, with - $\mathrm{COOH}$ functional groups (abbreviated as $\mathrm{Zr}(\mathrm{Iv})$-D113 hereafter) were both chosen for loading of $\mathrm{ZrO}^{2+}$ and testing of fluoride removal efficiency.

\section{Materials and methods}

\subsection{Chemicals and instruments}

The chemicals used in this study were of analytical grade and did not require further purification. Nitric acid $\left(\mathrm{HNO}_{3}\right)$, sodium hydroxide $(\mathrm{NaOH})$, sodium fluoride $(\mathrm{NaF})$, sodium nitrate $\left(\mathrm{NaNO}_{3}\right)$, sodium chloride $(\mathrm{NaCl})$, disodium hydrogen phosphate $\left(\mathrm{Na}_{2} \mathrm{HPO}_{4} \cdot 12 \mathrm{H}_{2} \mathrm{O}\right)$, sodium sulfate $\left(\mathrm{Na}_{2} \mathrm{SO}_{4}\right)$ and sodium carbonate $\left(\mathrm{Na}_{2} \mathrm{CO}_{3}\right)$ were purchased from Beijing Chemical Factory. Zirconium oxychloride octahydrate $\left(\mathrm{ZrOCl}_{2} \cdot 8 \mathrm{H}_{2} \mathrm{O}\right)$ was purchased from Tianjin Guangfu Fine Chemical Research Institute. The fluoride concentrations and $\mathrm{pH}$ values of the aqueous solutions were measured using a PF-1-C type fluoride ion selective electrode and a $\mathrm{pH}$ meter, respectively, which were purchased from Shanghai Yue-Ci Electronic Technology Co., Ltd. The morphologies and elemental compositions of the adsorbents were observed using a scanning electron microscope and energy dispersive spectrometer (ZEISS), and the composition of the functional group of the adsorbent was observed using a Fourier transform infrared spectrometer (IRTracer-100). The fluoride stock solution was prepared by dissolving $2.21 \mathrm{~g}$ of $\mathrm{NaF}$ in $1000 \mathrm{~mL}$ deionized water. In addition, other solutions of fluoride ions with different concentrations were prepared by diluting the stock solution.

\subsection{Preparation of $\operatorname{Zr}(\mathrm{Iv})$-loaded grape pomace}

The grape pomace used to prepare the adsorbent in this study was produced at the Xingtai Grape Wine Company, Hebei Province. First, the grape pomace was washed with deionized water several times to remove the contaminants on the surface of the grape pomace; then, by drying the cleaned grape pomace in an oven at $60{ }^{\circ} \mathrm{C}$ for 24 hours, the dried grape pomace was obtained and further crushed by a mechanical crusher, passed through a 40 mesh sieve, and collected for zirconium loading. Next, ten grams of dried grape pomace powder was added to $0.1 \mathrm{~mol} \mathrm{~L}^{-1} \mathrm{ZrOCl}_{2}$ $\cdot 8 \mathrm{H}_{2} \mathrm{O}$ solution with an initial $\mathrm{pH}$ of 1.35 . After stirring for 24 hours, the $\mathrm{pH}$ of the solution was found to be 1.11. After filtration, the filter cake was washed three times with deionized water to remove unloaded zirconium ions on the surface of the grape pomace, and the zirconium-loaded grape pomace was then dried in an oven at $60^{\circ} \mathrm{C}$. After drying for 24 hours, the prepared adsorbent was collected for defluoridation tests in the following experiments.

\subsection{Preparation of $\mathrm{Zr}(\mathrm{IV})-\mathrm{D} 001$ and $\mathrm{Zr}(\mathrm{Iv})-\mathrm{D} 113$}

The strongly acidic ion exchange resin D001 and the weakly acidic ion exchange resin D113 used in this study were purchased from Jiangsu Suqing Water Treatment Engineering Group Co., Ltd. First, pretreatment was performed for the D001 and D113 resins to remove various impurities and contaminants in the synthetic processes, and $10 \mathrm{~g}$ of each resin after pretreatment was added to a prepared $0.1 \mathrm{~mol} \mathrm{~L}^{-1} \mathrm{ZrOCl}_{2} \cdot 8 \mathrm{H}_{2} \mathrm{O}$ solution with an initial $\mathrm{pH}$ of 1.35. After stirring for 24 hours, the $\mathrm{pH}$ values of the $\mathrm{Zr}(\mathrm{IV})-\mathrm{D} 001$ and $\mathrm{Zr}$ (Iv)-D113 solutions shifted to 1.13 and 1.15 , respectively. After filtration, the resins were washed several times with deionized water to remove unloaded zirconium ions on the surface of the resins; then, the wet $\mathrm{Zr}$ (Iv)D001 and Zr(Iv)-D113 were placed in different labeled reagent bottles for use.

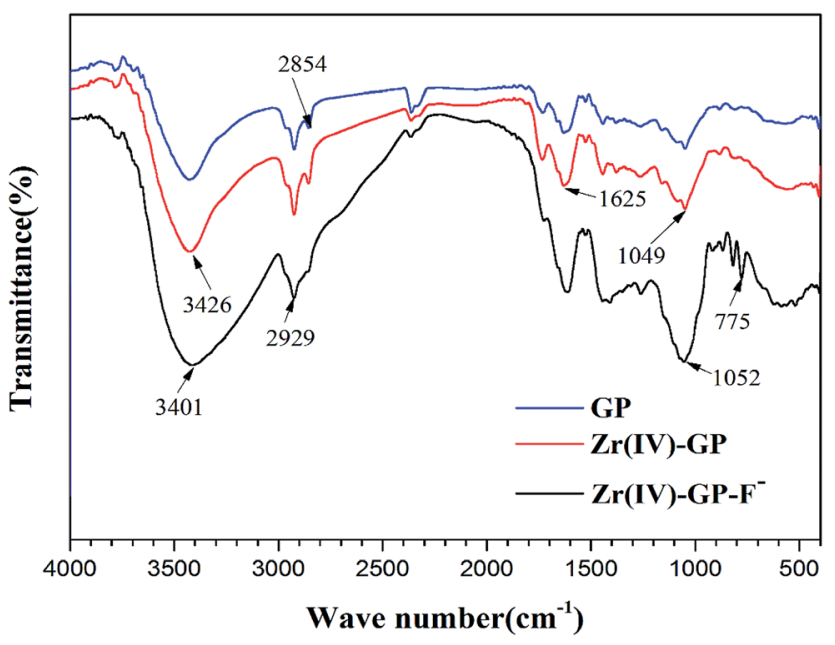

Fig. 1 FTIR spectra of raw grape pomace (GP), zirconium-loaded dried grape pomace ( $\mathrm{Zr}(\mathrm{IV})$-GP) and grape pomace with absorbed fluoride ( $\left.\mathrm{Zr}(\mathrm{IV})-\mathrm{GP}-\mathrm{F}^{-}\right)$in the range from 4000 to $400 \mathrm{~cm}^{-1}$. 

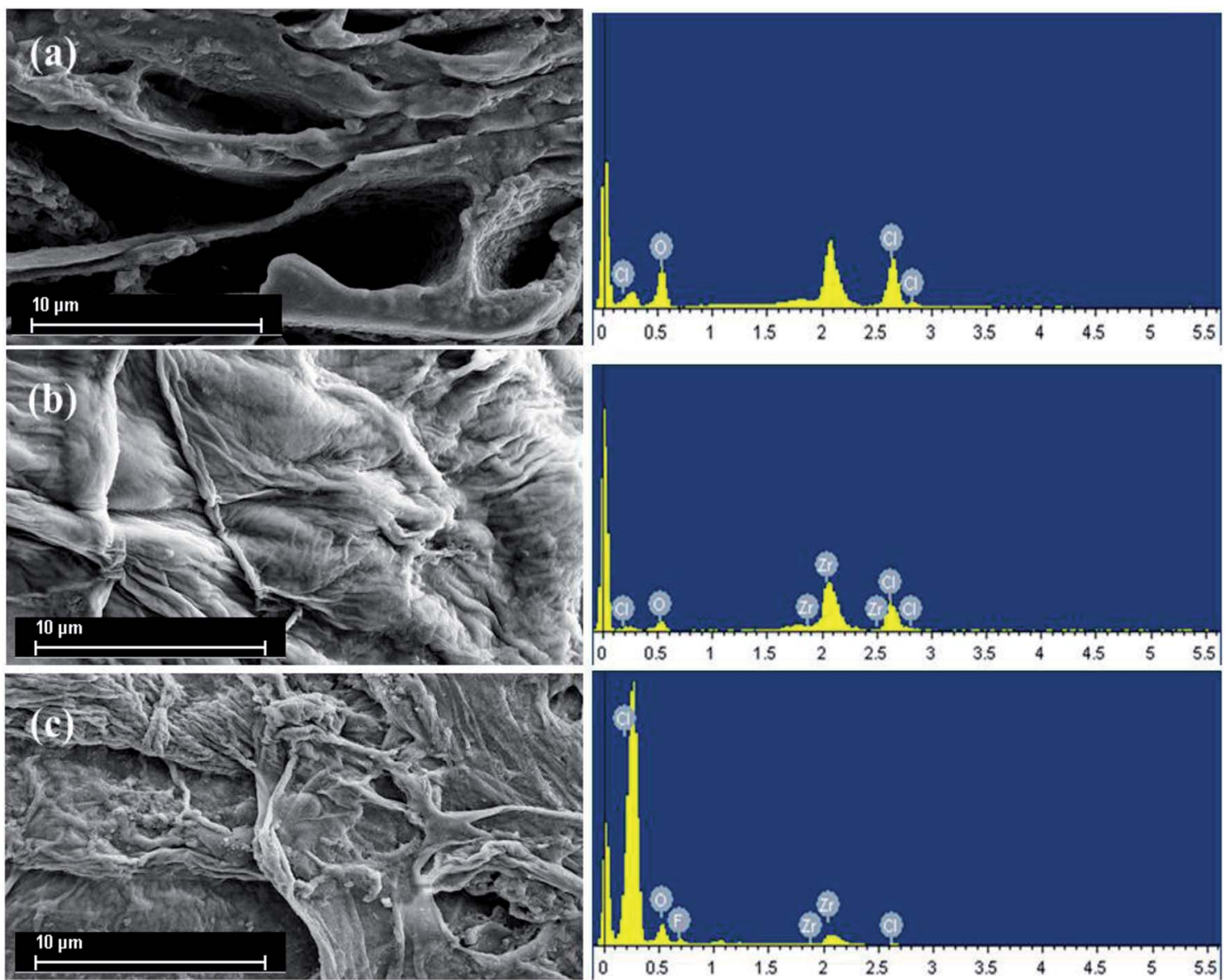

Fig. 2 SEM/EDS images of raw grape pomace (GP), zirconium-loaded dried grape pomace (Zr(IV)-GP) and grape pomace with adsorbed fluoride $\left(\mathrm{Zr}(\mathrm{IV})-\mathrm{GP}-\mathrm{F}^{-}\right)$

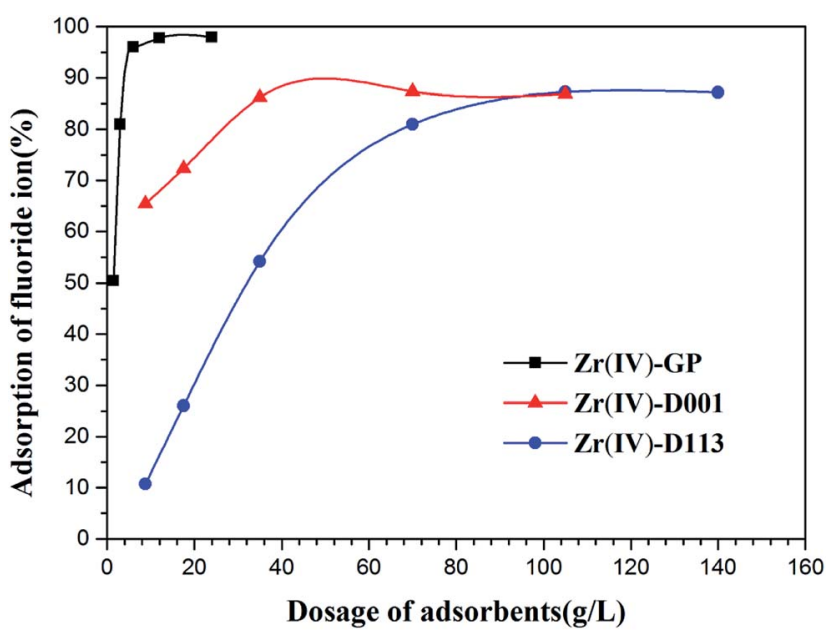

Fig. 3 Effects of adsorbent dosage on equilibrium time at different $S / L$ ratios of adsorbents (initial fluoride concentration $=19.91 \mathrm{mg} \mathrm{L}^{-1}, \mathrm{pH}_{\mathrm{i}}=3$, temperature $=25^{\circ} \mathrm{C}$, solution volume $=20 \mathrm{~mL}$, contact time $=60 \mathrm{~min}$ ).

\subsection{Characterization of the adsorbent}

Examination of GP, $\mathrm{Zr}$ (Iv)-GP and $\mathrm{Zr}$ (Iv)-GP-F ${ }^{-}$was carried out using a Fourier transform infrared spectrometer (IRTracer-100) to analyze the functional groups. Scanning electron microscopy

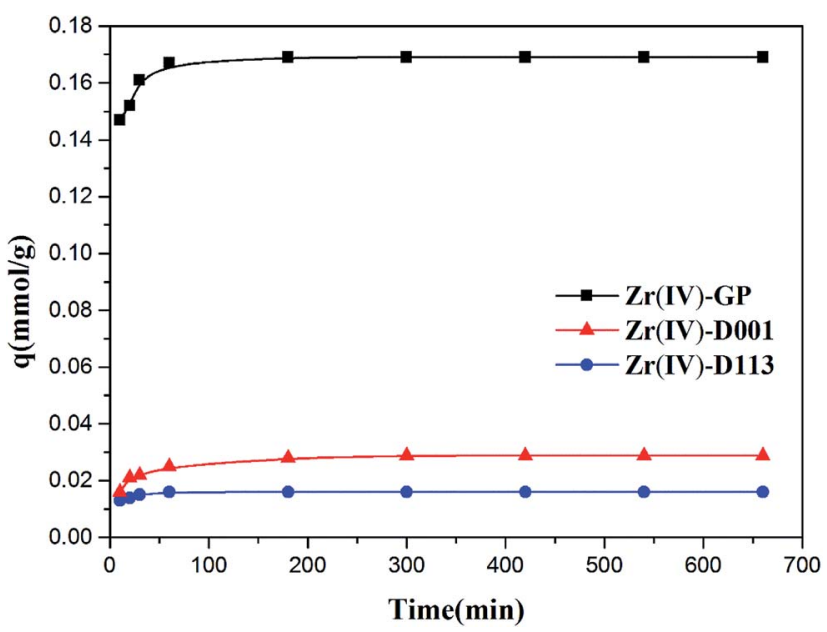

Fig. 4 Effects of contact time on fluoride adsorption using Zr(IV)-GP, $\mathrm{Zr}(\mathrm{IV})-\mathrm{D} 001$ and $\mathrm{Zr}(\mathrm{IV})-\mathrm{D} 113$ (initial fluoride concentration = $19.91 \mathrm{mg} \mathrm{L}^{-1}, \mathrm{pH}_{\mathrm{i}}=3$, temperature $=25^{\circ} \mathrm{C}$, solution volume $=20 \mathrm{~mL}$, weights of adsorbents $=120 \mathrm{mg}, 700 \mathrm{mg}, 700 \mathrm{mg}$, respectively).

(SEM) and energy dispersive spectrometry (EDS) were used to observe the surface morphologies and chemical compositions of the adsorbents before and after adsorption of zirconium ions 


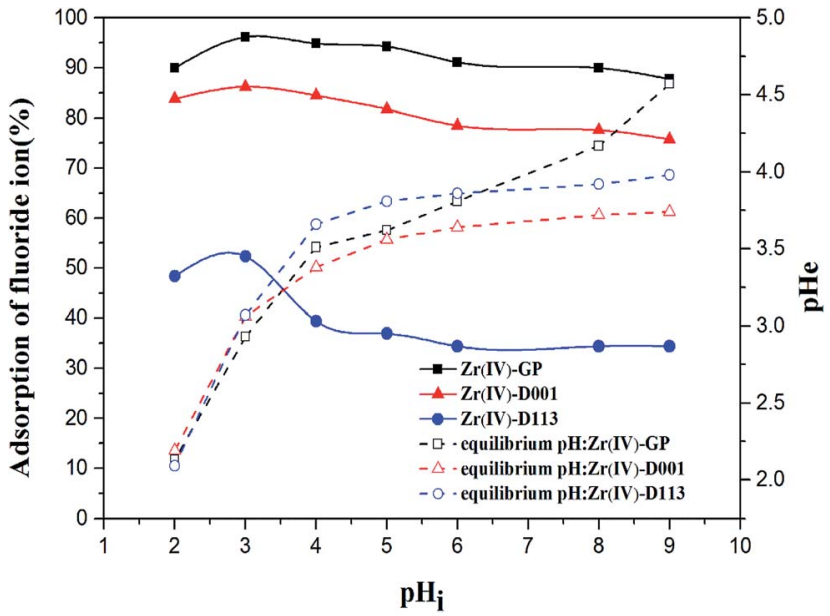

Fig. 5 Effects of $\mathrm{pH}_{\mathrm{i}}$ on fluoride adsorption using $\mathrm{Zr}(\mathrm{IV})-\mathrm{GP}, \mathrm{Zr}(\mathrm{IV})$ D001 and $Z r(I V)$-D113 (initial fluoride concentration $=19.91 \mathrm{mg} \mathrm{L}^{-1}$, temperature $=25{ }^{\circ} \mathrm{C}$, solution volume $=20 \mathrm{~mL}$, contact time $=$ $60 \mathrm{~min}$, weights of adsorbents $=120 \mathrm{mg}, 700 \mathrm{mg}, 700 \mathrm{mg}$, respectively).

and adsorption of fluoride. The amount of $\mathrm{Zr}(\mathrm{Iv})$ ions loaded on the GP was quantitatively evaluated by dissolving $20 \mathrm{mg}$ of $\mathrm{Zr}(\mathrm{Iv})$ $\mathrm{GP}$ in $8 \mathrm{~mL}$ of aqua regia. After filtration, the total concentration of zirconium ions loaded on the grape pomace was determined by ICP/AES. The amount of zirconium ions leaking during the adsorption of fluoride by $\mathrm{Zr}(\mathrm{Iv})$-GP was also tested by ICP/AES.

\subsection{Batchwise adsorption tests}

Batch adsorption experiments were performed for the three different adsorbents to investigate their adsorption performance for fluoride. Fluorine removal efficiency was investigated by controlling the time, amount of adsorbent, initial $\mathrm{pH}$ and initial fluoride concentration. The adsorption ratio and adsorption capacity were calculated by the following two equations:

$$
\begin{gathered}
\% A=\frac{C_{\mathrm{i}}-C_{\mathrm{e}}}{C_{\mathrm{i}}} \times 100 \% \\
q=\frac{C_{\mathrm{i}}-C_{\mathrm{e}}}{W} \times V
\end{gathered}
$$

where $C_{\mathrm{i}}$ and $C_{\mathrm{e}}$ are the initial concentration $\left(\mathrm{mg} \mathrm{L}^{-1}\right)$ and equilibrium concentration of fluoride, respectively. $W$ is the dry weight of the adsorbent (mg), and $V$ is the volume of fluoride solution $(\mathrm{mL})$.

Kinetic tests were carried out in order to study the equilibration times and the diffusion constants for fluoride adsorption. In each experiment, $120 \mathrm{mg}$ of $\mathrm{Zr}(\mathrm{Iv})-\mathrm{GP}$ adsorbent and $20 \mathrm{~mL}$ of fluoride solution $\left(19.91 \mathrm{mg} \mathrm{L}^{-1}\right)$ were mixed together and stirred for a certain time; then, $700 \mathrm{mg}$ wet $\mathrm{Zr}$ (Iv)-D001 and $\mathrm{Zr}$ (Iv)-D113 resins, which equated to $120 \mathrm{mg}$ dried adsorbents, were also mixed with $20 \mathrm{~mL}$ fluoride solution $\left(19.91 \mathrm{mg} \mathrm{L}^{-1}\right)$ and then stirred for a certain time. The adsorption isotherm of fluoride was investigated by changing the initial concentration of fluoride. The repeated adsorption-desorption of $\mathrm{Zr}(\mathrm{Iv})$-GP was carried out using $0.1 \mathrm{~mol} \mathrm{~L}^{-1} \mathrm{NaOH}$ to investigate the reusability of the $\mathrm{Zr}(\mathrm{Iv})-\mathrm{GP}$ adsorbent. (a)

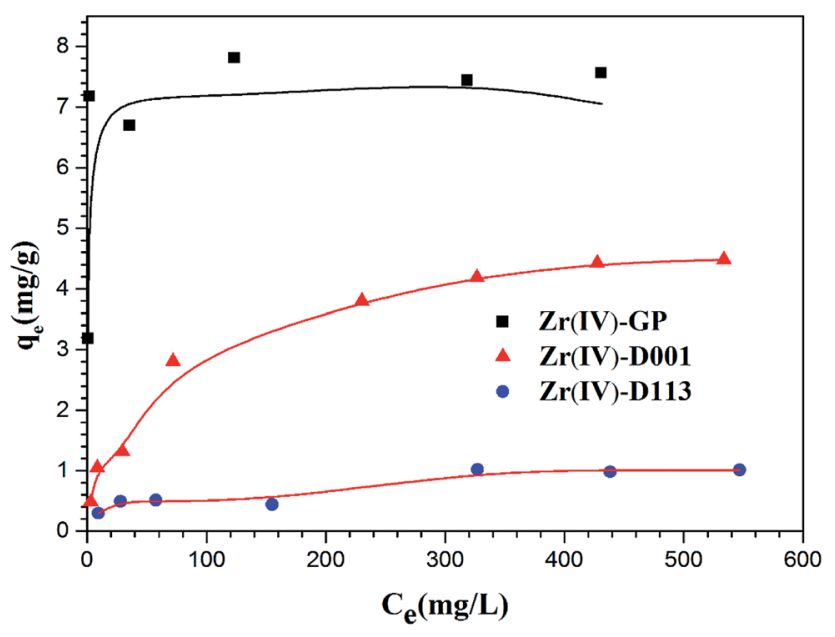

(b)

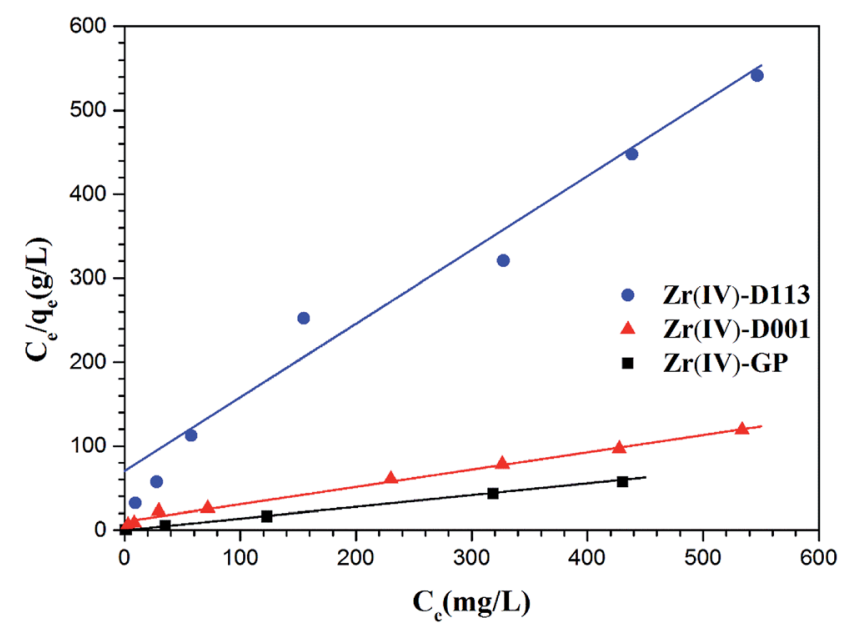

Fig. 6 (a) Adsorption isotherms of fluoride on $\mathrm{Zr}(\mathrm{IV})$-GP, Zr(IV)-D001 and $\operatorname{Zr}($ IV)-D113: (b) corresponding Langmuir plots (initial fluoride concentration $=19.91 \mathrm{mg} \mathrm{L}^{-1}$, temperature $=25^{\circ} \mathrm{C}, \mathrm{pH}_{\mathrm{i}}=3$, solution volume $=20 \mathrm{~mL}$, contact time $=60 \mathrm{~min}$, weights of adsorbents = $120 \mathrm{mg}, 700 \mathrm{mg}, 700 \mathrm{mg}$, respectively).

Table 1 Isotherm parameters for fluoride adsorption on various adsorbents from aqueous solution

\begin{tabular}{lllll}
\hline & \multicolumn{3}{l}{ Langmuir model parameters } & \\
\cline { 2 - 5 } Adsorbent & $\mathrm{pH}$ & $q_{\max }\left(\mathrm{mg} \mathrm{g}^{-1}\right)$ & $b\left(\mathrm{~L} \mathrm{mg}^{-1}\right)$ & $R^{2}$ \\
\hline Zr(Iv)-GP & 3.0 & 7.54 & 1.121 & 0.99 \\
Zr(Iv)-D001 & 3.0 & 4.85 & 0.020 & 0.96 \\
Zr(Iv)-D113 & 3.0 & 1.14 & 0.013 & 0.88 \\
\hline
\end{tabular}

\subsection{Continuous adsorption and elution tests}

The capability of $\mathrm{Zr}$ (Iv)-GP to remove fluoride from water and the regeneration performance of the adsorbent were evaluated using a continuous fixed bed column with an inner diameter and height of $1.0 \mathrm{~cm}$ and $25 \mathrm{~cm}$, respectively. The fluoride in the 
fixed bed experiment was set initially at $10.03 \mathrm{mg} \mathrm{L}^{-1}$, the initial $\mathrm{pH}$ at 3.0 , the flow rate at $1.0 \mathrm{~mL} \mathrm{~min}^{-1}$, and the amount of adsorbent at $500 \mathrm{mg}$. The column adsorption experiment was carried out until the fluoride concentration of the effluent approached the initial concentration. The effluent fluoride concentration was analyzed by a fluoride ion-selective electrode. When the continuous adsorption experiment was complete, the fixed bed column was washed several times with deionized water and then desorbed using $0.1 \mathrm{~mol} \mathrm{~L}^{-1} \mathrm{NaOH}$.

\section{Results and discussion}

\subsection{Characterization of $\operatorname{Zr}(\mathrm{Iv})$-GP}

3.1.1. Analysis of infrared (IR) spectra. In order to investigate the compositions of the adsorbent functional groups, infrared spectroscopy analysis was performed on raw grape pomace (GP), $\mathrm{Zr}$ (Iv)-GP and fluoride-adsorbed $\mathrm{Zr}$ (Iv)-GP, respectively. As shown in Fig. 1, the strong peaks observed for the original GP at $3423,2927,1739$ and $1631 \mathrm{~cm}^{-1}$ are related to the stretching vibrations of $-\mathrm{OH},-\mathrm{CH}_{2},-\mathrm{COO}$ and $-\mathrm{C}=\mathrm{O}$, respectively. The peak value of $1631 \mathrm{~cm}^{-1}$ changed to $1625 \mathrm{~cm}^{-1}$ after loading zirconium ions, which may be due to ion exchange between the hydrogen ions on the grape pomace and the zirconium ions. Therefore, infrared spectroscopy indicates that carbonyl functional groups play a key role in zirconium ion loading. The fixed zirconium ions in the grape pomace form hydrate compounds, which have anion exchange capability with fluoride ions in aqueous solution to remove fluoride from water.

3.1.2. Analysis of SEM and EDS. As shown in Fig. 2, the morphologies and elemental compositions of the original grape pomace (GP), zirconium-loaded grape pomace ( $\mathrm{Zr}(\mathrm{Iv})-\mathrm{GP})$ and grape pomace after adsorption of fluoride $\left(\mathrm{Zr}(\mathrm{Iv})-\mathrm{GP}_{-} \mathrm{F}^{-}\right)$were analyzed by scanning electron microscopy (SEM) and energy dispersive spectrometry (EDS), respectively. Fig. 2(a) shows a cross-section of the original grape pomace; the surface is porous and has a large surface area, which should provide

Table 2 Comparison of adsorption capacities for fluoride on different adsorbents

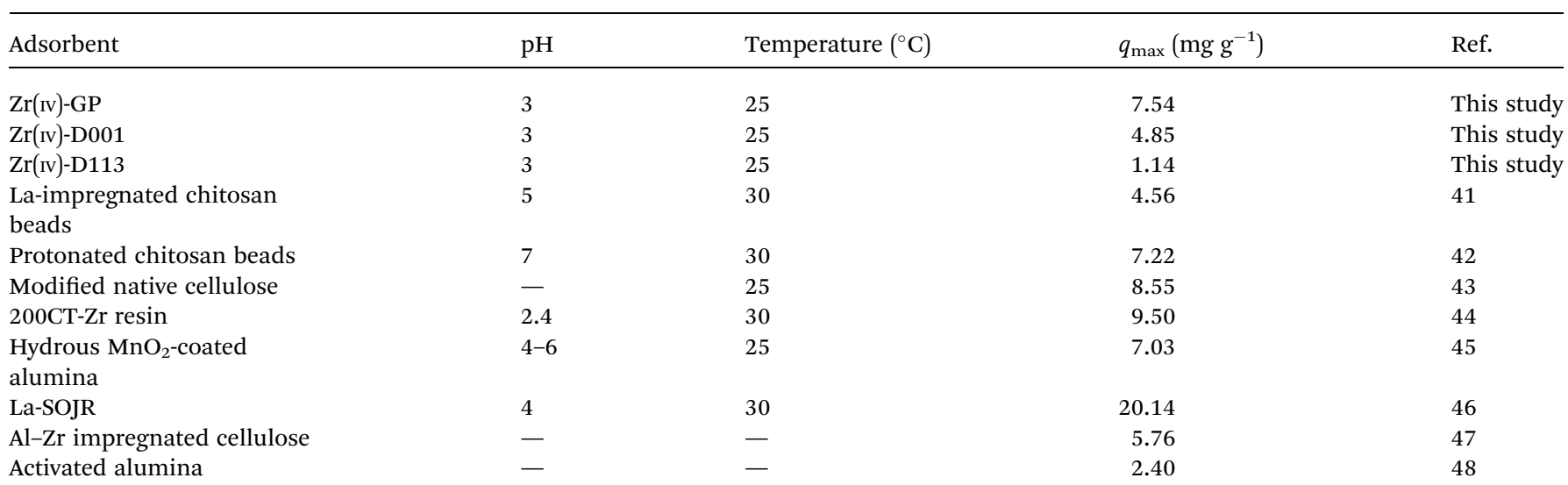

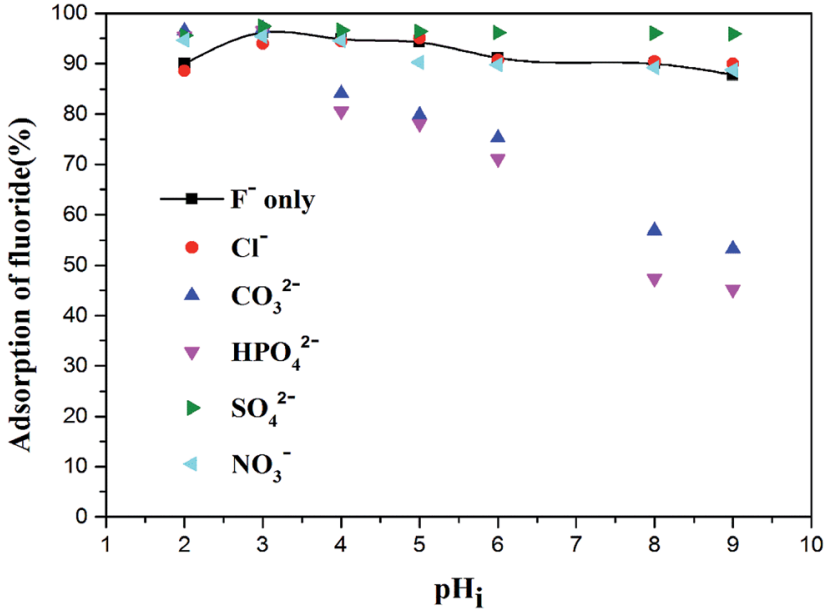

Fig. 7 Effects of co-existing interfering ions during the adsorption of fluoride onto $\mathrm{Zr}(\mathrm{Iv})$ - GP (initial fluoride concentration $=19.91 \mathrm{mg} \mathrm{L}^{-1}$, temperature $=25{ }^{\circ} \mathrm{C}$, solution volume $=20 \mathrm{~mL}$, contact time $=$ $60 \mathrm{~min}$, weight of adsorbents $=120 \mathrm{mg}, \mathrm{pH}_{\mathrm{i}}=3$ ).

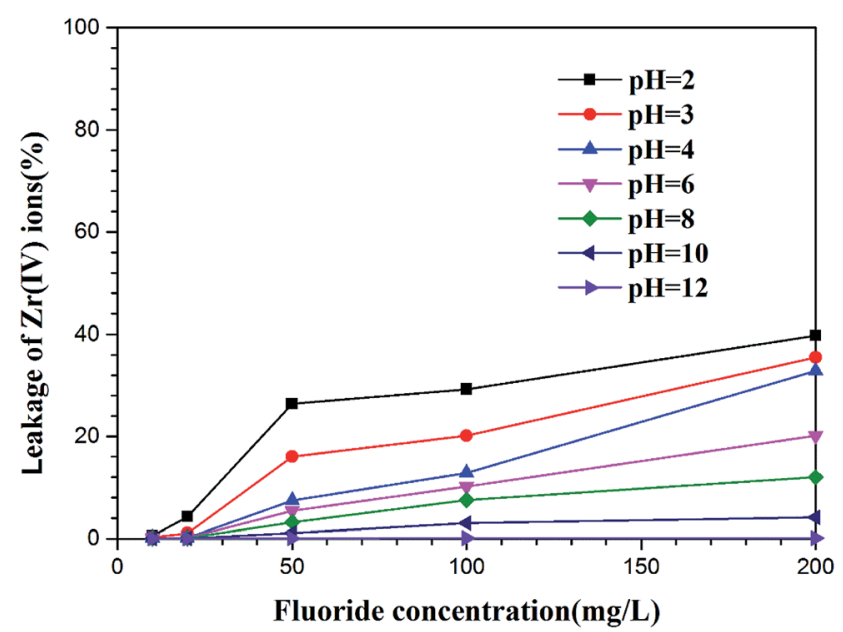

Fig. 8 Leakage of loaded zirconium ion from Zr(IV)-GP with varying concentrations of fluoride at different $\mathrm{pH}$ values (temperature $=25^{\circ} \mathrm{C}$, solution volume $=20 \mathrm{~mL}$, contact time $=60 \mathrm{~min}$, weight of adsorbent $=120 \mathrm{mg}$ ). 
convenient conditions for the loading of zirconium ions and fluoride ions, and the raw grape pomace is mainly composed of $\mathrm{C}, \mathrm{Cl}$ and $\mathrm{O}$ elements. Fig. 2(b) shows the epidermal morphology after loading zirconium ions. It is apparent from the energy spectrum that a large number of zirconium ions are loaded on the surface of the grape pomace to form the active sites. Fig. 2(c) shows the epidermal morphology after adsorption of fluoride; the energy spectrum shows that fluoride ions were also successfully adsorbed, which can be ascribed to ion exchange.

\subsection{Batchwise adsorption tests}

3.2.1. Effects of adsorbent dosage. In order to investigate the effects of the amount of adsorbent on the adsorption efficiency, the amount of $\operatorname{Zr}(\mathrm{rv})-\mathrm{GP}$ was varied from $30 \mathrm{mg}$ to $480 \mathrm{mg}$ and the wet $\mathrm{Zr}(\mathrm{Iv})$-D001 and $\mathrm{Zr}(\mathrm{Iv})-\mathrm{D} 113$ were varied from $175 \mathrm{mg}$ to $2800 \mathrm{mg}$, corresponding to the same dried mass values of $\mathrm{Zr}(\mathrm{Iv})-\mathrm{GP}$. The initial concentration of fluoride was $19.91 \mathrm{mg} \mathrm{L}^{-1}$, the volume of the solution was $20 \mathrm{~mL}$, and the initial $\mathrm{pH}$ was set at 3 . As shown in Fig. 3, adsorption equilibrium could be achieved when $120 \mathrm{mg}$ of $\mathrm{Zr}$ (Iv)-GP was added; however, for $\mathrm{Zr}(\mathrm{IV})$-D001 and $\mathrm{Zr}(\mathrm{IV})$-D113, reaction equilibrium was attained at $700 \mathrm{mg}$ and $1400 \mathrm{mg}$, respectively. This indicates that the adsorption efficiency of $\operatorname{Zr}(\mathrm{Iv})$-GP for fluoride removal is much higher than those of $\operatorname{Zr}(\mathrm{Iv})$-D001 and $\mathrm{Zr}(\mathrm{Iv})$ D113.

3.2.2. Effects of contact time. Experiments to investigate the effects of adsorbent contact time on fluoride adsorption on $\operatorname{Zr}(\mathrm{Iv})-\mathrm{GP}, \operatorname{Zr}(\mathrm{Iv})$-D001 and $\mathrm{Zr}(\mathrm{Iv})$-D113 were carried out in the time range of $10 \mathrm{~min}$ to $300 \mathrm{~min}$. The initial concentration of fluoride was $19.91 \mathrm{mg} \mathrm{L}^{-1}$, the initial $\mathrm{pH}$ was set at 3 , and the amounts of $\operatorname{Zr}(\mathrm{Iv})-\mathrm{GP}, \operatorname{Zr}(\mathrm{Iv})-\mathrm{D} 001$ and $\operatorname{Zr}(\mathrm{Iv})-\mathrm{D} 113$ were set at 120, 700, and $1400 \mathrm{mg}$, respectively. As shown in Fig. 4, the amount of fluoride adsorbed at the beginning increased rapidly with time, and all samples reached equilibrium after $1 \mathrm{~h}$ of contact. The equilibrium adsorption amounts of $\mathrm{Zr}(\mathrm{rv})-\mathrm{GP}$, $\mathrm{Zr}(\mathrm{Iv})-\mathrm{D} 001$ and $\mathrm{Zr}(\mathrm{Iv})-\mathrm{D} 113$ were 3.21, 0.532 and $0.304 \mathrm{mg} \mathrm{g}^{-1}$, respectively; it was obvious that the biosorbent had the advantage of much greater adsorption capacity for fluoride.

3.2.3. Effects of $\mathbf{p H}$. The initial $\mathrm{pH}$ of the solution plays a crucial role in fluoride adsorption; it may affect the number of chemically active sites by changing the surface charging state under different $\mathrm{pH}$ values. In order to determine the optimum $\mathrm{pH}$, the initial $\mathrm{pH}$ of the solution was varied between 2 and 9. As shown in Fig. 5, when the $\mathrm{pH}$ was set at 3 , the adsorption performance of all three adsorbents exhibited the best efficiency, and the highest adsorption efficiency of $\mathrm{Zr}$ (Iv)-GP reached $96.13 \%$. In the above studies, it could be found that when the initial $\mathrm{pH}$ of the solution was greater than 5 , the adsorption ratio became poor; this is obviously due to competition of $-\mathrm{OH}$ at higher $\mathrm{pH}$ and also because the surface negative charges of $\mathrm{Zr}(\mathrm{Iv})$-GP at $\mathrm{pH}$ values above 5 became fairly strong, which repels the approaching fluoride anions strongly, as demonstrated in Fig. 2 (ESI). $\dagger^{38,39}$ In batchwise tests, it was found that when the initial $\mathrm{pH}$ was adjusted to $9, \mathrm{Zr}(\mathrm{Iv})$-GP retained a good adsorption effect for fluoride, and the adsorption ratio could reach $87.74 \%$. By monitoring the $\mathrm{pH}$ before and after the reaction, it was found that the main reason for the above phenomenon was that $\mathrm{Zr}(\mathrm{Iv})$-GP itself can lower the $\mathrm{pH}$ of the solution to below 5 , thereby avoiding the interference of hydroxyl ions in the adsorption of fluoride ions by the adsorbent. It is an important finding that $\mathrm{Zr}$ (Iv)-GP can effectively remove fluoride from a fluorine-containing aqueous solution in the case of $\mathrm{pH}$ values greater than 5 and without adjusting the $\mathrm{pH}$ in advance. Obviously, the protons were released from the $\mathrm{Zr}(\mathrm{Iv})$-GP biosorbent. Additionally, the raw grape pomace gel was used to test its adsorption for fluoride; no removal efficiency was confirmed, which verifies that the existence of zirconium in the grape pomace specifically contributed to its removal efficiency for fluoride.

3.2.4. Adsorption isotherms of fluoride. As shown in Fig. 6(a), the adsorption isotherms of fluoride by the $\mathrm{Zr}(\mathrm{Iv})-\mathrm{GP}$, $\operatorname{Zr}(\mathrm{Iv})$-D001 and $\operatorname{Zr}(\mathrm{Iv})-\mathrm{D} 113$ adsorbents were tested and compared. As shown, when the concentration is low, the rising curve is quite steep. When the concentration is higher, the curve approaches a platform, which is consistent with the typical single-layer adsorption law. The experimental data were modeled using the Langmuir model, and the formula is as follows: ${ }^{40}$

$$
\frac{C_{\mathrm{e}}}{q_{\mathrm{e}}}=\frac{1}{q_{\max } b}+\frac{C_{\mathrm{e}}}{q_{\max }}
$$

where $C_{\mathrm{e}}\left(\mathrm{mg} \mathrm{L}^{-1}\right)$ and $q_{\mathrm{e}}\left(\mathrm{mg} \mathrm{g}^{-1}\right)$ in the formula are the adsorption equilibrium concentration and the adsorption amount, respectively. $q_{\max }\left(\mathrm{mg} \mathrm{g}^{-1}\right)$ is the maximum adsorption capacity and $b\left(\mathrm{~L} \mathrm{mg}^{-1}\right)$ is the Langmuir constant, which is an adsorption equilibrium constant related to the binding energy associated with the adsorption process. Fig. 6(b) shows the adsorption isotherm fitted according to formula (3). The maximum adsorption capacities and constants $b$ of the three adsorbents can be calculated from the fitted formula, as listed

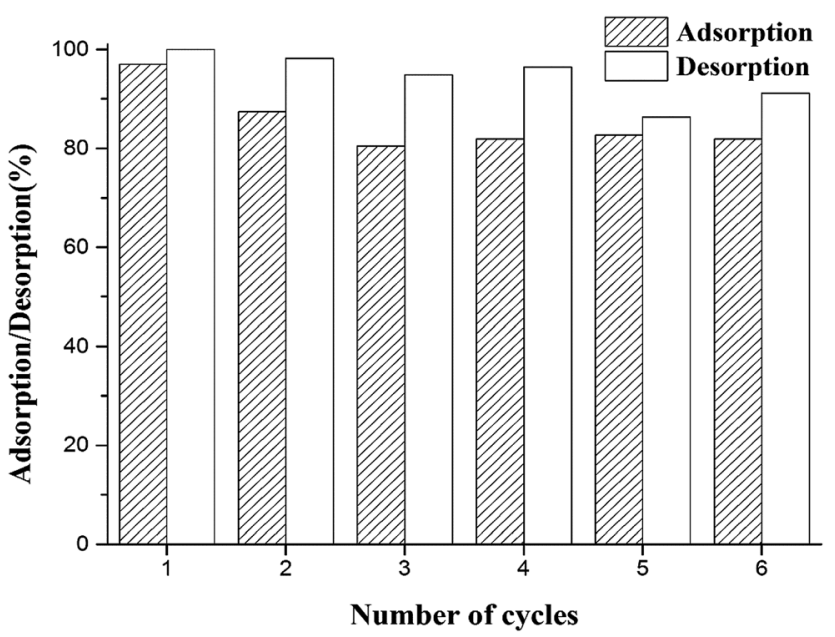

Fig. 9 Adsorption/desorption cycle tests of Zr(Iv)-GP (initial fluoride concentration $=1.8 \mathrm{mg} \mathrm{L}^{-1}$, initial $\mathrm{pH}_{\mathrm{i}}=3$, temperature $=25^{\circ} \mathrm{C}$, solution volume $=20 \mathrm{~mL}$, contact time $=60 \mathrm{~min}$, weight of adsorbent $=120 \mathrm{mg}$ ). 
in Table 1. As seen from the table, the maximum adsorption capacity of $\mathrm{Zr}(\mathrm{Iv})-\mathrm{GP}$ is $7.54 \mathrm{mg} \mathrm{L}^{-1}$, which is much larger than those of the other two adsorbents. Also, the correlation coefficients of the three adsorbents are close to 1 for fitting, which further indicates that the adsorption behavior is consistent with the Langmuir model. Table 2 lists the maximum adsorption capacities and optimum $\mathrm{pH}$ values of adsorbents tested by other researchers. It can be seen from the table that the maximum adsorption capacity of the adsorbent used in this study is much larger than those of most other adsorbents; also, the adsorbent used in this study is low-cost, safe and non-toxic, and does not cause secondary pollution to the environment, demonstrating good prospective real applications in the defluoridation of groundwater which contains excessive fluoride.

3.2.5. Effects of co-existing ions. There are usually some interfering impurity ions in actual fluorine-containing water.
Therefore, this experiment explored the effects of various interfering ions on the selective fluorine removal efficiency of Zr(Iv)-GP. As shown in Fig. 7, the effects of some high concentration anions, such as chloride, nitrate, carbonate, phosphate and sulfate, on the selective fluorine removal of $\mathrm{Zr}$ (Iv)-GP at different $\mathrm{pH}$ values were investigated. It can be seen from the figure that $100 \mathrm{mg} \mathrm{L}^{-1}$ of sulfate, nitrate and chloride did not influence the selective defluoridation of $\mathrm{Zr}$ (Iv)-GP, while high concentrations of carbonates and phosphates had adverse effects on the selective removal of fluoride using $\mathrm{Zr}$ (Iv)-GP.

3.2.6. Leakage of loaded $\mathrm{Zr}(\mathrm{Iv})$ ions from grape pomace. As mentioned, fluoride ions form very stable complexes with highvalent metal ions such as $\mathrm{Fe}^{3+}, \mathrm{Al}^{3+}$ and $\mathrm{ZrO}^{2+}$, according to the study of Taishi Kobayashi and Kenso Fujiwara; ${ }^{49,50}$ the $\operatorname{Zr}(\mathrm{IV}$ ) loaded in the grape pomace may leak into the water due to possible coordination with fluoride anions in the defluoridation

\section{(a)}

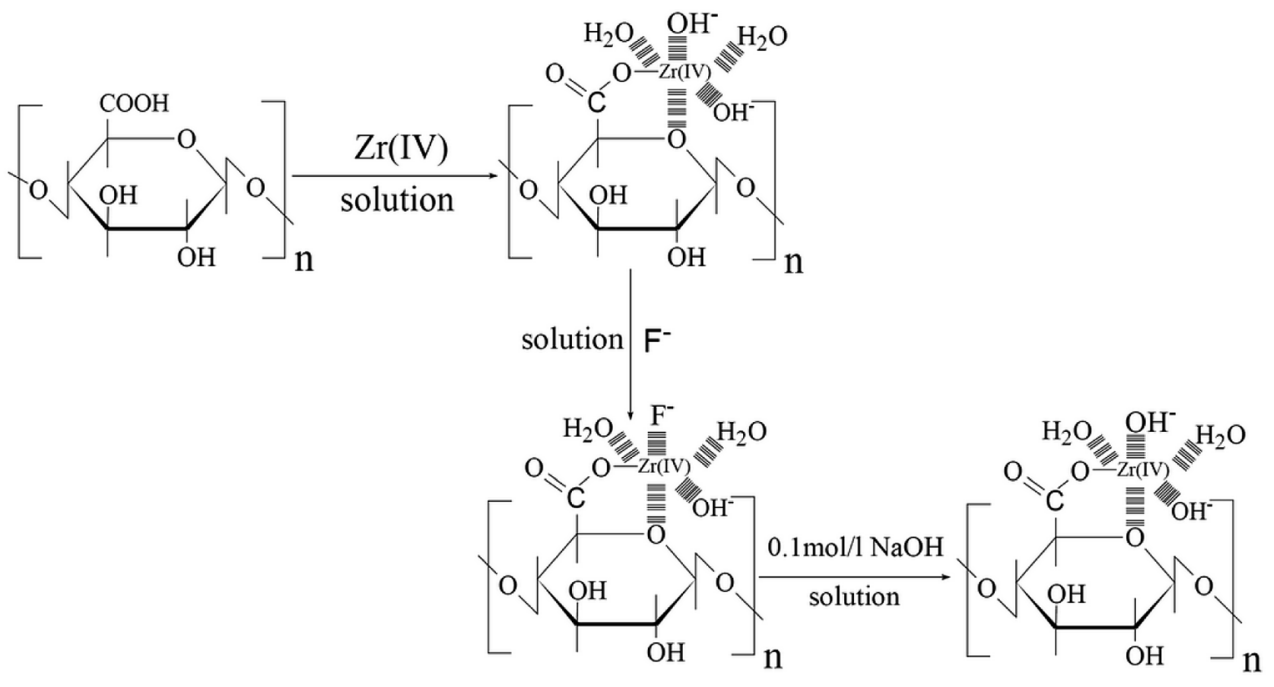

(b)

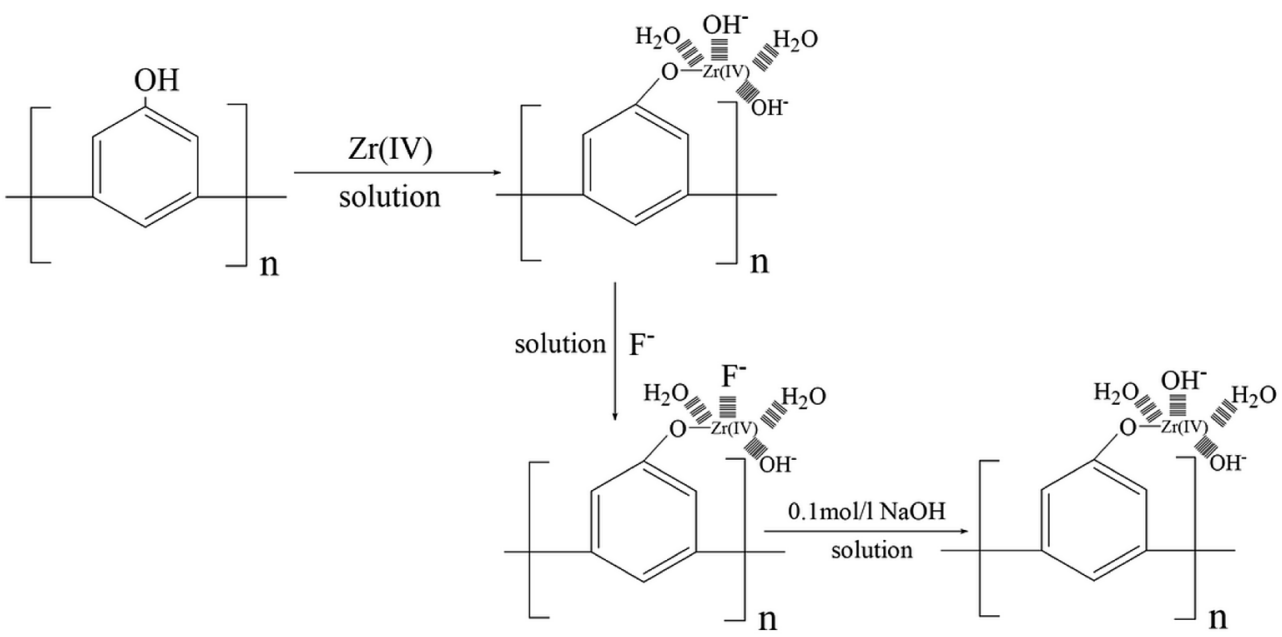

Scheme 1 Mechanism of fluoride adsorption and desorption on the $\mathrm{Zr}(\mathrm{IV})$-loaded grape pomace particles. 
process, especially under acidic conditions. The present study explores the effects of fluoride concentration and $\mathrm{pH}$ on the leakage of loaded zirconium ions from the grape pomace. As shown in Fig. 8, at low $\mathrm{pH}$, when the initial fluoride concentration is below $20 \mathrm{mg} \mathrm{L}^{-1}$, the amount of $\mathrm{Zr}$ (Iv) leakage is negligible for all the investigated $\mathrm{pH}$ values. However, as the initial concentration of fluoride increases, the amount of $\operatorname{Zr}(\mathrm{Iv}$ ) leakage into the solutions increases. At high $\mathrm{pH}$, even at high concentrations of fluoride ions, the leakage of $\mathrm{Zr}(\mathrm{Iv})$ is negligible at alkaline $\mathrm{pH}$, indicating that the desorption of the fluoride by $0.1 \mathrm{~mol} \mathrm{~L}^{-1} \mathrm{NaOH}$ does not cause any leakage of the supported metal ions.

3.2.7. Adsorption/desorption studies on $\mathrm{Zr}$ (Iv)-GP. In order to investigate the reutilization performance of the adsorbent, a series of adsorption-desorption-adsorption experiments were carried out. The initial concentration of fluoride was set at $19.91 \mathrm{mg} \mathrm{L}^{-1}$, and the initial $\mathrm{pH}$ of the solution was 3. Previous studies have shown that sodium hydroxide solution can effectively desorb adsorbed fluoride; therefore, the adsorbent was eluted using $0.1 \mathrm{~mol} \mathrm{~L}^{-1} \mathrm{NaOH}$ in the present study. As shown in Fig. 9, after six consecutive cycles of adsorption-desorption, the adsorbent retained very good adsorption efficiency, and the adsorption ratio reached over $80 \%$. The above results show that $\mathrm{Zr}$ (Iv)-GP can maintain good adsorption capacity even after several repeat uses, which can greatly reduce its cost in practical applications.

3.2.8. Fluoride adsorption/desorption mechanism. According to a study by Ilce Gabriela Medina-Meza, ${ }^{51}$ large numbers of chemical groups such as polyphenols and anthocyanins can be extracted from grape pomace, and it also contains large amounts of pectic acid and other substances. The presence of these substances provides abundant active sites for the loading of zirconium ions via a cation exchange process. As shown in Scheme 1a, the residual carboxyl groups on pectic acid, whose main component is a polysaccharide polymer existing in the form of a free acid, form a stable metal chelate with zirconium ions. During the loading process, all the positive charges of the supported metal zirconium ions are unlikely to be electro-neutralized by the carboxyl groups because the large polymeric chains of pectic acid have large steric hindrance. Therefore, the loaded zirconium has only one or two positive charges, and the other zirconium ions are probably electroneutralized by various anions, such as hydroxide ions present in water. The hydroxide ions are anion-exchanged with fluoride in the water to remove fluoride ions in the water. Additionally, this adsorption mechanism also can be shown in Scheme $1 \mathrm{~b}$; grape pomace contains large amounts of polyphenolic substances, the hydroxyl groups on the polyphenolic substances form stable chelates with the metal zirconium ions, and the metal zirconium ions are also neutralized by various anions, such as hydroxide ions, present in the water. These hydroxide ions undergo ligand exchange with anions during adsorption to remove fluorine from the water. ${ }^{52,53}$ The adsorbed fluoride ion can be eluted with $\mathrm{NaOH}$ and also by ligand exchange reactions between fluoride ion and hydroxide ion.

\subsection{Column tests}

In order to provide guidance for practical applications on a large scale, the present study evaluated the ability of $\mathrm{Zr}(\mathrm{Iv})$-GP to

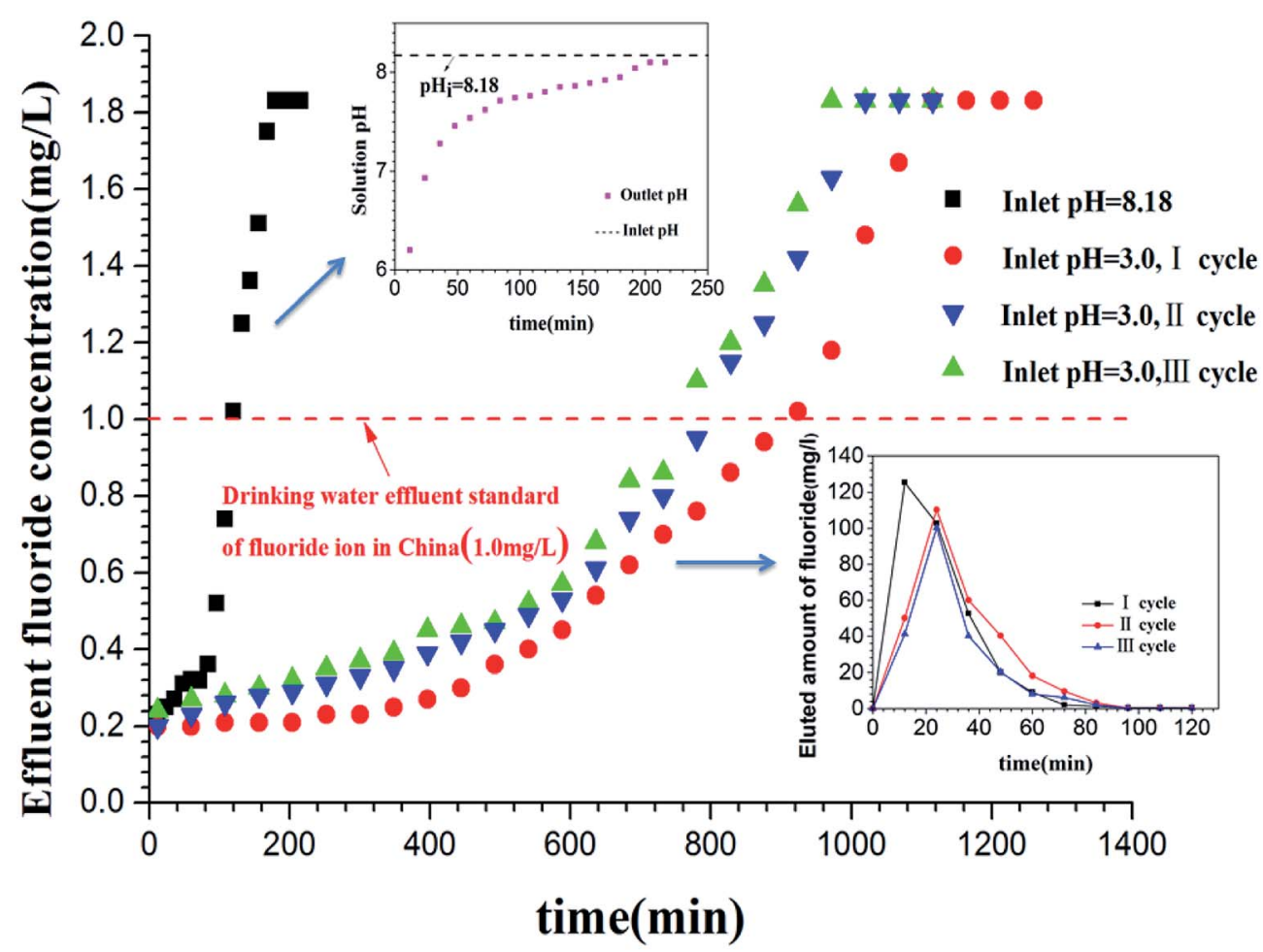

Fig. 10 Breakthrough curve of real groundwater in a fixed bed column with $\operatorname{Zr}(\mathrm{IV})-\mathrm{GP}$ (initial fluoride concentration $=1.8 \mathrm{mg} \mathrm{L}^{-1}$, temperature $=$

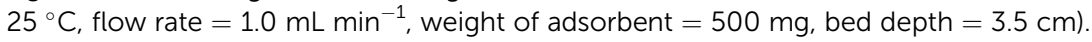


remove fluoride in a continuous fixed bed column. A real groundwater sample containing $1.8 \mathrm{mg} \mathrm{L}^{-1}$ fluoride taken from Guanzhuang Village in Haixing County of Hebei Province, China, was used for the continuous column defluoridation test. Firstly, the groundwater was directly percolated through the $\mathrm{Zr}(\mathrm{Iv})$-GP packed column without pre-tuning the $\mathrm{pH}$; as shown in Fig. 10, the breakthrough point was about $120 \mathrm{~min}$. The $\mathrm{pH}$ of the outlet water was 6.20 in the early run and increased gradually with flowing time, reaching the original $\mathrm{pH}$ of the groundwater at 8.18. Obviously, the protons in the $\mathrm{Zr}$ (Iv)-GP gel leaked into the flowing water, leading to a decrease in the $\mathrm{pH}$ of the early inlet water; however, it was consumed quickly and no longer caused a $\mathrm{pH}$ increase of the outlet water after a period of time. Taking the defluoridation efficiency into account, the $\mathrm{pH}$ of the inlet groundwater was adjusted by acidification in advance. Fig. 10 indicates that the groundwater at $\mathrm{pH} 3.0$ increased the defluoridation capacity to at least 8 times than that at the $\mathrm{pH}$ of the original groundwater sample (8.18). Two and three cycles of adsorption/elution operations caused the defluoridation efficiency to decrease gradually; however, at least $80 \%$ of the adsorption capacity was retained. Fig. 10 also demonstrates that after elution using $0.1 \mathrm{~mol} \mathrm{~L}^{-1} \mathrm{NaOH}$ solution, the fluoride concentration in the eluent reached $125.3 \mathrm{mg} \mathrm{L}^{-1}$, which is about 70 times higher than the initial fluoride concentration $\left(1.8 \mathrm{mg} \mathrm{L}^{-1}\right)$. The above experiments show that the fixed bed column equipped with $\operatorname{Zr}(\mathrm{Iv})$-GP adsorbent has good removal performance for trace fluoride in water. This study provides the possibility of practical application of the adsorbent for the defluoridation of groundwater.

\section{Conclusion}

This study reports a new type of fluorine-removing biomaterial which has been experimentally confirmed to provide superior defluoridation of zirconium-loaded grape pomace in comparison with traditional resins. Energy dispersive X-ray (EDS) spectroscopy, Fourier transform infrared (FTIR) spectroscopy and other techniques confirmed that fluoride ions were successfully adsorbed on $\operatorname{Zr}(\mathrm{Iv})$-GP. The Langmuir isotherm model well describes the equilibrium data of fluoride adsorption on $\operatorname{Zr}(\mathrm{Iv})-\mathrm{GP}$. Column adsorption tests verified that preadjusting the groundwater $\mathrm{pH}$ increased the fluoride removal capacity by about 8 times that of the original groundwater $\mathrm{pH}$ of 8.18. After three cycles of adsorption/elution, the defluoridation efficiency decreased slightly, showing that $\mathrm{Zr}(\mathrm{Iv})-\mathrm{GP}$ is an excellent fluorine removal material that may find real application in the practical groundwater purification field.

\section{Conflicts of interest}

There are no conflicts to declare.

\section{Acknowledgements}

The present work was financially supported by the special fundamental funds by Beijing Education Committee Cooperation Building Foundation Project for the project of agri- biowaste reuse for toxic metals removal (Grant No. 00012245) and the fundamental funds by Beijing Science Committee for the project of the defluoridation novel technologies of groundwater (Grant No. 00012247).

\section{References}

1 P. Loganathan, S. Vigneswaran, J. Kandasamy and R. Naidu, J. Hazard. Mater., 2013, 248-249(6), 1-19.

2 J. Nunes-Pereira, R. Lima, G. Choudhary, P. R. Sharmad, S. Ferdovb, G. Botelhoe, R. K. Sharmad and S. LancerosMéndez, Sep. Purif. Technol., 2018, 205, 1-10.

3 D. L. Ozsvath, Rev. Environ. Sci. Biotechnol., 2009, 8(1), 59-79.

4 M. Mohapatra, S. Anand, B. K. Mishra, E. G. Dion and P. Singh, J. Environ. Manage., 2010, 91(1), 67-77.

5 P. Miretzky and A. F. Cirelli, J. Fluorine Chem., 2011, 132(4), 231-240.

6 B. B. Wang, B. S. Zheng, C. Zhai, G. Q. Yu and X. J. Liu, Environ. Int., 2004, 30(8), 1067-1073.

7 S. V. Jadhav, G. D. Yadav, V. K. Rathod and K. V. Marathe, J. Environ. Manage., 2015, 162, 306-325.

8 D. Chakraborti, M. M. Rahman, A. Chatterjee, D. Das, B. Das, B. Nayaka, A. Pal, U. K. Chowdhury, S. Ahmed, B. K. Biswas, M. K. Sengupta, D. Lodh, G. Samanta, S. Chakrabortya, M. M. Roy, R. N. Dutta, K. C. Sahaf, S. C. Mukherjee, S. Pati and P. B. Kar, J. Trace Elem. Med. Biol., 2016, 38, 33-45. 9 M. A. Hossain, M. M. Rahman, M. Murrill, B. Das, B. Roy, S. Dey, D. Maity and D. Chakraborti, Sci. Total Environ., 2013, 463-464, 1217-1224.

10 F. D. Belkada, O. Kitous, N. Drouiche, S. Aoudj, O. Bouchelaghem, N. Abdi, H. Grib and N. Mameri, Sep. Purif. Technol., 2018, 204, 108-115.

11 A. Y. Bagastyo, A. D. Anggrainy and C. S. Nindita, Sustainable Environ. Res., 2017, 27, 230-237.

12 G. J. Millar, S. J. Couperthwaite and D. B. Wellner, Journal of Water Process Engineering, 2017, 20, 113-122.

13 J. Markovski, J. Garcia, K. D. Hristovski and P. Westerhoff, Sci. Total Environ., 2017, 599-600, 1848-1855.

14 J. Shen and A. Schäfer, Chemosphere, 2014, 117(1), 679-691. 15 M. Tahaikt, R. E. Habbani, A. A. Haddou, I. Achary, Z. Amor, M. Taky, A. Alami, A. Boughriba, M. Hafsi and A. Elmidaoui, Desalination, 2007, 212(1), 46-53.

16 S. V. Jadhav, K. V. Marathe and V. K. Rathod, Journal of Water Process Engineering, 2016, 13, 153-167.

17 M. V. V. N. Samrat, K. K. Rao, A. K. Sengupta, J. Riotte and J. R. Mudakavi, Journal of Water Process Engineering, 2018, 23, 327-337.

18 H. Huang, J. Liu, P. Zhang, D. Zhang and F. Gao, Chem. Eng. J., 2017, 307, 696-706.

19 C. Zhang, Y. Z. Li, T. J. Wang, Y. P. Jiang and J. Fok, Appl. Surf. Sci., 2017, 425, 272-281.

20 W. C. Yang, S. Q. Tian, Q. Z. Tang, L. Y. Chai and H. Y. Wang, J. Colloid Interface Sci., 2017, 496, 496-504.

21 K. Zhang, S. Wu, J. He, L. Chen, X. G. Cai, K. Chen, Y. L. Li, B. Sun, D. Y. Lin, G. Q. Liu, L. T. Kong and J. H. Liu, J. Colloid Interface Sci., 2016, 475, 17-25. 
22 A. Nagaraj, K. K. Sadasivuni and M. Rajan, Carbohydr. Polym., 2017, 176, 402-410.

23 J. Y. He, K. Chen, X. G. Cai, Y. L. Li, C. G. Wang, K. S. Zhang, Z. Jin, F. L. Meng, X. G. Wang, L. T. Kong and J. H. Liu, J. Colloid Interface Sci., 2017, 490, 97-107.

24 J. Y. He, K. S. Zhang, S. B. Wu, X. G. Cai, K. Chen, Y. L. Li, B. S. Sun, Y. Jia, F. L. Meng, Z. Jin, L. T. Kong and J. H. Liu, J. Hazard. Mater., 2016, 303, 119-130.

25 U. Kumari, S. K. Behera and B. C. Meikap, J. Hazard. Mater., 2019, 365, 868-882.

26 Y. G. Gan, X. M. Wang, L. Zhang, B. D. Wu, G. Y. Zhang and S. J. Zhang, Chemosphere, 2019, 218, 860-868.

27 C. Choe Earn, K. Minhee and Y. Seyoon, J. Taiwan Inst. Chem. Eng., 2018, 93, 306-314.

28 Y. Li, C. Zhang, Y. Jiang and T. J. Wang, Chemosphere, 2018, 200, 554-560.

29 K. U. Ahamad, R. Singh, I. Baruah, H. Choudhury and M. R. Sharma, Groundw. Sustain. Dev., 2018, 7, 452-458.

30 B. Ekka, R. S. Dhaka, R. K. Patel and P. Dash, J. Cleaner Prod., 2017, 151, 303-318.

31 S. Chatterjee and S. De, Sep. Purif. Technol., 2014, 125(125), 223-238.

32 N. M. Zúñiga-Muro, A. Bonilla-Petriciolet, D. I. MendozaCastillo, H. E. Reynel-Ávila and J. C. Tapia-Picazo, J. Fluorine Chem., 2017, 197, 63-73.

33 E. M. Nigri, A. Bhatnagar and S. D. F. Rocha, J. Cleaner Prod., 2017, 142, 3558-3570.

34 C. K. Rojas-Mayorgaa, A. Bonilla-Petricioleta, I. A. AguayoVillarreal, V. Hernández-Montoya, M. R. Moreno-Virgen, R. Tovar-Gómez and M. A. Montes-Morán, J. Anal. Appl. Pyrolysis, 2013, 104, 10-18.

35 X. Wu, Y. Zhang, X. Dou, B. Zhao and M. Yang, Chem. Eng. J., 2013, 223, 364-370.

36 L. Fang, K. N. Ghimire, M. Kuriyama and K. Inoue, J. Chem. Technol. Biotechnol., 2003, 78, 1038-1047.

37 C. E. Choonga, M. Kimb, S. Yoonc, G. Lee and C. M. Parke, J. Taiwan Inst. Chem. Eng., 2018, 93, 306-314.
38 H. Paudyal, B. Pangeni, K. Inoue, H. Kawakita, K. Ohto and S. Alam, Bioresour. Technol., 2013, 146, 713-720.

39 H. Paudyal, B. Pangeni, K. Inoue, H. Kawakita, K. Ohto, H. Harada and S. Alam, J. Hazard. Mater., 2011, 192, 676682.

40 H. Paudyal, B. Pangeni, K. Inoue, H. Harada, H. Kawakita, K. Ohto and S. Alam, Int. J. Mater. Sci. Appl., 2017, 6(4), 212-222.

41 A. Bansiwal, D. Thakre, N. Labhshetwar, S. Meshramb and S. Rayalu, Colloids Surf., B, 2009, 74(1), 216-224.

42 N. Viswanathan, C. S. Sundaram and S. Meenakshi, J. Hazard. Mater., 2009, 161(1), 423-430.

43 Y. Tian, M. Wu, R. Liu, D. Wang, X. B. Lina, W. L. Liu, L. Ma and Y. D. Li, J. Hazard. Mater., 2011, 185(1), 93-100.

44 H. Paudyal, B. Pangeni, K. Inoue, M. Matsueda, R. Suzuki, H. Kawakita, K. Ohto, B. K. Biswas and S. Alam, Sep. Sci. Technol., 2012, 47(1), 96-103.

45 S. X. Teng, S. G. Wang, W. X. Gong, X. W. Liu and B. Y. Gao, J. Hazard. Mater., 2009, 168(2), 1004-1011.

46 H. Paudyal, B. Pangeni, K. N. Ghimire, K. Inoue, K. Ohto, H. Kawakita and S. Alam, Chem. Eng. J., 2012, 195-196, 289-296.

47 M. Barathi, K. K. A. Santhana and N. Rajesh, J. Environ. Chem. Eng., 2013, 1(4), 1325-1335.

48 M. Barathi, K. K. A. Santhana and N. Rajesh, J. Environ. Chem. Eng., 2013, 1(4), 1325-1335.

49 T. Kobayashi, T. Sasaki, I. Takagi and H. Moriyama, J. Nucl. Sci. Technol., 2009, 46(2), 142-148.

50 K. Fujiwara, H. Yamana, T. Fujii and H. Moriyama, J. Nucl. Sci. Technol., 2002, 39, 290-293.

51 I. G. Medina-Meza and V. G. Barbosa-Cánovas, J. Food Eng., 2015, 166, 268-275.

52 Y. L. Tang, X. H. Guan, T. Z. Su, N. Y. Gao and J. M. Wang, Colloids Surf., A, 2009, 337, 33-38.

53 H. Paudyal, B. Pangeni, K. Inoue, H. Kawakita, K. Ohto and S. Alam, J. Chem. Eng. Jpn., 2012, 45, 331-336. 